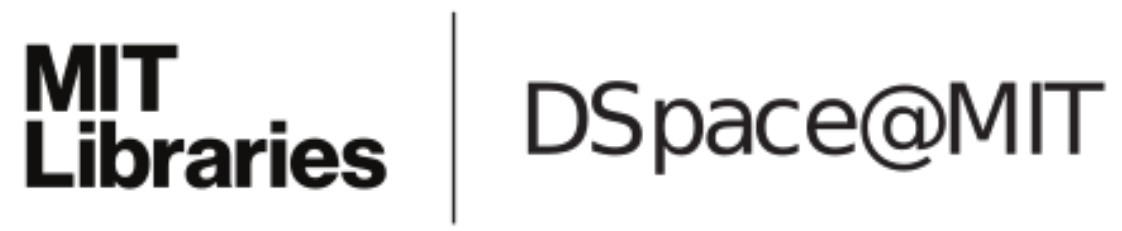

\author{
MIT Open Access Articles
}

\begin{abstract}
Helicobacter pylori Infection Promotes Methylation and Silencing of Trefoil Factor 2, Leading to Gastric Tumor Development in Mice and Humans
\end{abstract}

The MIT Faculty has made this article openly available. Please share how this access benefits you. Your story matters.

Citation: Peterson, Anthony J., Trevelyan R. Menheniott, Louise O'Connor, Anna K. Walduck, James G. Fox, Kazuyuki Kawakami, Toshinari Minamoto, et al. "Helicobacter Pylori Infection Promotes Methylation and Silencing of Trefoil Factor 2, Leading to Gastric Tumor Development in Mice and Humans." Gastroenterology 139, no. 6 (December 2010): 2005-2017.

As Published: http://dx.doi.org/10.1053/j.gastro.2010.08.043

Publisher: Elsevier

Persistent URL: http://hdl.handle.net/1721.1/99371

Version: Author's final manuscript: final author's manuscript post peer review, without publisher's formatting or copy editing

Terms of use: Creative Commons Attribution 
Published in final edited form as:

Gastroenterology. 2010 December ; 139(6): 2005-2017. doi:10.1053/j.gastro.2010.08.043.

\title{
Helicobacter pylori Infection Promotes Methylation and Silencing of Trefoil Factor 2, Leading to Gastric Tumor Development in Mice and Humans
}

\author{
Anthony J. Peterson ${ }^{\star}$, Trevelyan R. Menheniott ${ }^{\star}$, Louise O'Connor ${ }^{\star}$, Anna K. Walduck ${ }^{\ddagger}$, \\ James G. Fox ${ }^{\S}$, Kazuyuki Kawakami", Toshinari Minamoto", Eng Kok Ong", Timothy C. \\ Wang $^{\#}$, Louise M. Judd ${ }^{*, * *}$, and Andrew S. Giraud ${ }^{*, * \star}$ \\ "Murdoch Children's Research Institute, Royal Children's Hospital, Flemington Road, Parkville, \\ Victoria \\ ‡Department of Microbiology and Immunology, University of Melbourne, Parkville, Victoria, \\ Australia \\ §Division of Comparative Medicine, Department of Biological Engineering, MIT, Cambridge, \\ Massachusetts \\ "Division of Translational and Clinical Oncology, Cancer Research Institute, Kanazawa \\ University, Kanazawa, Japan \\ ISequenom Platform Facility, Murdoch Children's Research Institute, Royal Children's Hospital, \\ Flemington Road, Parkville, Victoria, Australia \\ \#Division of Digestive and Liver Diseases, Columbia University Medical School, New York, New \\ York \\ ${ }^{* *}$ Department of Paediatrics, University of Melbourne, Royal Children's Hospital, Flemington \\ Road, Parkville, Victoria, Australia
}

\section{Abstract}

BACKGROUND \& AIMS-Trefoil factors (TFFs) regulate mucosal repair and suppress tumor formation in the stomach. Tffl deficiency results in gastric cancer, whereas Tff2 deficiency increases gastric inflammation. TFF2 expression is frequently lost in gastric neoplasms, but the nature of the silencing mechanism and associated impact on tumorigenesis have not been determined.

METHODS-We investigated the epigenetic silencing of TFF2 in gastric biopsy specimens from individuals with Helicobacter pylori-positive gastritis, intestinal metaplasia, gastric cancer, and disease-free controls. TFF2 function and methylation were manipulated in gastric cancer cell

\footnotetext{
(C) 2010 by the AGA Institute

Reprint requests. Address requests for reprints to: Andrew S. Giraud, Murdoch, Children's Research Institute, Royal Children's Hospital, Flemington, Road, Parkville, Victoria, 3052 Australia. andrew.giraud@ mcri.edu.au; fax: (61) 399366528.

A.J.P. and T.R.M. contributed equally and should be considered co-first authors.

L.M.J. and A.S.G. contributed equally and should be considered co-senior authors.

Supplementary Material

Note: To access the supplementary material accompanying this article, visit the online version of Gastroenterology at www.gastrojournal.org, and at doi:10.1053/j.gastro.2010.08.043.

Conflicts of interest

The authors disclose no conflicts.
} 
lines. The effects of $T f f 2$ deficiency on tumor growth were investigated in the $g p 130^{\mathrm{F} / \mathrm{F}}$ mouse model of gastric cancer.

RESULTS-In human tissue samples, DNA methylation at the TFF2 promoter began at the time of $H$ pylori infection and increased throughout gastric tumor progression. TFF2 methylation levels were inversely correlated with $T F F 2$ messenger RNA levels and could be used to discriminate between disease-free controls, $H$ pylori-infected, and tumor tissues. Genome demethylation restored $T F F 2$ expression in gastric cancer cell lines, so $T F F 2$ silencing requires methylation. In Tff2-deficient $g$ p $130^{\mathrm{F} / \mathrm{F}} / T f f 2^{-l-}$ mice, proliferation of mucosal cells and release of $\mathrm{T}$ helper cell type-1 (Th-1) 1 cytokines increased, whereas expression of gastric tumor suppressor genes and Th- 2 cytokines were reduced, compared with $g p 130^{\mathrm{F} / \mathrm{F}}$ controls. The fundus of $g p 130^{\mathrm{F} / \mathrm{F}} / T f f 2^{-/-}$ mice displayed glandular atrophy and metaplasia, indicating accelerated preneoplasia.

Experimental $H$ pylori infection in wild-type mice reduced antral expression of Tff 2 by increased promoter methylation.

CONCLUSIONS-TFF2 negatively regulates preneoplastic progression and subsequent tumor development in the stomach, a role that is subverted by promoter methylation during $\mathrm{H}$ pylori infection.

\section{Keywords}

Tumor Suppressor; Epigenetics; Stomach Cancer; Trefoil Factor 2

The trefoil factors (TFF) 1 , TFF2, and TFF3 form a family of secreted proteins characterized by a triple loop structure, the trefoil domain. ${ }^{1}$ Gastric TFF 1 expression is restricted to surface mucus and pit epithelium of the fundus and antrum, whereas TFF2 is expressed in fundic mucus neck cells (MNCs), antrum, and duodenal Brunner's glands. ${ }^{2,3}$ TFF3 expression is restricted to intestinal goblet cells. ${ }^{4}$ TFF functions include mucus stabilization and barrier protection, ${ }^{5}$ regulation of cell migration during wound healing, 6,7 gastric cell differentiation, ${ }^{8}$ proliferation, and apoptosis. ${ }^{9,10}$

A body of published evidence shows that TFF1 is a stomach-specific tumor suppressor gene (TSG). Tff $1^{-/}$mice spontaneously develop antral/pyloric tumors, ${ }^{10}$ and antral tumors in the gp130 $0^{\mathrm{Y} 757 \mathrm{~F} / \mathrm{Y} 757 \mathrm{~F}}\left(g p 130^{\mathrm{F} / \mathrm{F}}\right)$ mouse model of gastric cancer show reduced Tffl

expression. ${ }^{11}$ Approximately half of all human gastric cancers show loss of TFF1 expression ${ }^{12}$ through loss of heterozygosity and promoter methylation ${ }^{13}$ as well as transcriptional inhibition by regulatory molecules. ${ }^{14}$ TFF1 inhibits gastric cancer cell line growth, ${ }^{15}$ blocks G1/S phase cell cycle progression, increases Retinoblastoma gene expression, ${ }^{9}$ and promotes gastric differentiation, ${ }^{16}$ all consistent with a tumor suppressor role in the stomach.

By contrast, the role of TFF2 in gastric cancer progression is less well understood. TFF2 expression is rapidly induced in gastrointestinal ulcerative pathologies particularly in regenerating epithelium ${ }^{17}$ or after nonsteroidal anti-inflammatory (NSAID) drug treatment. ${ }^{18}$ Moreover, in vivo delivery of recombinant TFF2 ameliorates mucosal damage. ${ }^{19}$

TFF2 gives its former name to a mucus metaplasia, of mainly fundic origin known as spasmolytic polypeptide expressing metaplasia (SPEM) ${ }^{20}$ Whereas SPEM is associated with Helicobacter pylori-dependent fundic gland atrophy ${ }^{21}$ and may be a precursor to gastric cancer, ${ }^{22}$ TFF 2 is dispensable for the development of SPEM-like metaplasia. ${ }^{23}$ In addition, Tff2-deficient mice display only subtle alterations in mucosal proliferation, parietal cell activation, and reduced reparative function. ${ }^{18}$ 
An anti-inflammatory role for Tff 2 has recently been described. Tff2-deficient mice display immune deregulation and are more susceptible to dextran sodium sulphate-induced colitis and Helicobacter felis-induced gastritis, developing more severe inflammatory pathology than wild-type controls. ${ }^{24,25}$ Furthermore, $H$ pylori-infected Tff2-deficient mice develop more advanced premalignant lesions of atrophy, metaplasia, and dysplasia than wild-type littermates. ${ }^{26}$ Therefore, in addition to immune modulation, TFF2 may impose growth restraint and limit neoplastic progression in the context of chronic inflammation.

Here, we demonstrate that loss of TFF2 expression occurs during the progression of human intestinal-type gastric cancer via the acquisition of aberrant promoter methylation. To determine the likely functional impact of $T F F 2$ loss (via promoter methylation) on gastric tumor growth, we have employed a genetic approach to disrupt Tff2 function in murine gastric cancer. The $g p 130^{\mathrm{Y} 757 \mathrm{~F} / \mathrm{Y} 757 \mathrm{~F}}\left(\mathrm{gp} 130^{\mathrm{F} / \mathrm{F}}\right)$ mouse is a model of gastric tumorigenesis that develops antral tumors with histopathologic similarities to human intestinal-type gastric cancer. ${ }^{27}$ We show that genetic $T f f 2$ deficiency substantially accelerates tumor growth in $g p 130^{\mathrm{F} / \mathrm{F}}$ mice, primarily via further loss of gastric TSGs and misexpression of hormones and cytokines that promote preneoplastic fundic atrophy and chronic gastritis. These data support the view that $T F F 2$ may act locally to suppress preneoplastic change and subsequent gastric tumor development, a role that is ultimately subverted by epigenetic silencing after $H$ pylori infection.

\section{Materials and Methods}

\section{Mice}

$T f f 2^{+/-}$and $g p 130^{\mathrm{F} /+}$ heterozygous mice ${ }^{11,18}$ were crossed to obtain wild-type, Tff2 $2^{-/-}$, $g p 130^{\mathrm{F} / \mathrm{F}}$, and compound mutant $g p 130^{\mathrm{F} / \mathrm{F}} / \mathrm{Tff}^{-/-}$mice and maintained on a C57BL6/129-

Sv mixed background. Age-matched littermate controls were used in all experiments. Wildtype (C57BL6) mice were infected with $H$ pylori Sydney strain 1 (SS1) as described. ${ }^{26}$ Experiments were performed in accordance with either the Royal Melbourne Hospital (approval No. 010/2005) or Murdoch Children's Research Institute Animal Ethics Committee (approval No. A583).

\section{Human Tissue Sources}

Gastric mucosal tissue was obtained from $H$ pylori-positive individuals and disease-free controls as described. ${ }^{28}$ Gastric cancers and matched preneoplastic adjacent to cancer tissues were obtained with informed consent (approval No. 174.2008; Kanazawa University Ethics Committee for Human Genome Research).

\section{Morphometric and Histologic Analysis}

Mouse stomachs were removed, pinned, and photographed for macroscopic morphometry. Paraffin sections $(4 \mu \mathrm{m})$ stained with $\mathrm{H} \& \mathrm{E}$ or alcian blue periodic acid-Schiff (AB/PAS) were used for microscopic morphometry and histologic assessment. Morphometric analysis was performed using ImageJ software (http://rsb.info.nih.gov/ij/index.html; National Institutes of Health, Bethesda, MD). The gastric mucosal area and length were outlined with the calibrated software drawing tool at the appropriate magnification. Inflammation was assessed by microscopy in a blinded fashion on AB/PAS and H\&E-stained sections. Antral tumor tissues were analyzed with a minimum of 3 separate samples per animal cut and scored according to the density of inflammatory cells from minimum $=0$ to maximum $=3^{29}$ including infiltration around the muscularis mucosa, submucosal inflammation, and intramucosal infiltration of the tumors. 


\section{Mammalian Cell Culture}

AGS and MKN28 gastric cancer cell lines were maintained in RPMI 1640 Glutamax I growth medium, $10 \%$ fetal bovine serum, $2 \mathrm{mmol} / \mathrm{L}$ nonessential amino acids, $50 \mathrm{IU} / \mathrm{mL}$ penicillin, $50 \mu \mathrm{g} / \mathrm{mL}$ streptomycin (all Invitrogen, Carlsbad, CA), at $37^{\circ} \mathrm{C}$ in a humidified incubator with $5 \% \mathrm{CO}_{2} /$ air.

For proliferation analysis, AGS cells were serum starved overnight then seeded in 6-well plates at $2 \times 10^{5}$ cells/well in growth medium supplemented with $0.2 \%$ fetal bovine serum. Recombinant human (rh) TFF2 was used at $50 \mu \mathrm{g} / \mathrm{mL}$. Viable cell counts were performed by $0.4 \%$ trypan blue dye exclusion on a hemocytometer. For apoptosis, cells were stained with annexin V-Alexa Fluor 488 conjugate (Invitrogen Molecular Probes, Carlsbad, CA) and propidium iodide according to the manufacturer's protocols. Apoptotic (annexin V positive, propidium iodide negative) cells (10,000 events) were resolved on an LSRII flow cytometer (BD Biosciences, San Diego, CA) and analyzed using FACS Diva software (BD Biosciences). For genome demethylation studies, AGS and MKN28 cells were plated in 25$\mathrm{cm}$ flasks at $5 \times 10^{5}$ cells and allowed to attach overnight. Cells were treated with $10 \mu \mathrm{mol} / \mathrm{L}$ $5^{\prime}$-aza-2'-deoxycytidine (5'-Aza-dC) dissolved in dimethyl sulfoxide (Sigma) or dimethyl sulfoxide alone for 72 hours, with fresh $5^{\prime}$-Aza-dC added at 24-hour intervals.

\section{Quantitative DNA Methylation Analysis}

Genomic DNA was isolated from tissue using the DNeasy tissue kit (Qiagen, Hilden, Germany) or using Trizol (Invitrogen) and $200-500 \mathrm{ng}$ of each sample was bisulphite converted using Zymo EZ DNA methylation reagents (Zymo Research, Orange, CA) according to the manufacturer's protocols. $T F F 2$ promoter fragments were recovered from bisulphite-converted DNA by polymerase chain reaction (PCR) (full details in Supplementary Materials and Methods). Quantitative methylation analysis of bisulphite PCR-amplified products was performed with the EPITYPER system (Sequenom Inc, San Diego, CA) using MassCLEAVE reagents (Sequenom) followed by matrix-assisted laser desorption ionization time-of-flight mass spectrometry. ${ }^{30}$ Data cleaning and 2-way hierarchical cluster analysis were performed using the R script gplots software (available: http://www.r-project.org/).

\section{Results}

TFF2 Epigenetic Silencing by Progressive Promoter Methylation During Human IntestinalType Gastric Cancer Development

To examine potential epigenetic mechanisms underlying loss of TFF2 expression, we performed correlative TFF2 messenger RNA (mRNA) expression and promoter methylation analysis on gastric mucosal specimens collected from 4 pathologic subgroups. These included normal stomach, $H$ pylori-positive gastritis ${ }^{31}$ (Supplementary Table 1), intestinaltype gastric cancer, and patient matched preneoplastic adjacent tissue showing intestinal metaplasia (IM) (Supplementary Table 2). Quantitative reverse transcription and polymerase chain reaction (QRT-PCR) (Supplementary Materials and Methods) revealed progressive loss of TFF2 expression in $H$ pylori-positive gastritis (fold change: $-3.33 \pm 0.77 ; P=.035$ ), IM (fold change: $-4.22 \pm 0.679 ; P=.009$ ), and gastric cancer (fold change: $-5021.53 \pm$ $2513.59 ; P<.001$ ) compared with normal stomach (Figure $1 A$ ). Next, we quantified CpG methylation in the TFF2 promoter region and first exon (Figure 1B) using the Sequenom EPI-TYPER assay. EPITYPER is equivalent to the bisulphite mutagenesis and sequencing technique in resolving methylation on individual $\mathrm{CpG}$ dinucleotides (Supplementary Figure 1) but superior in terms of quantitation, intrasample precision, and sample throughput. TFF2 promoter methylation was significantly increased to a similar degree in $\mathrm{H}$ pylori-positive gastritis and IM tissues, respectively, but substantially increased in gastric cancer compared 
with normal controls (Figure $1 C$ ) with the most pronounced differences observed at $\mathrm{CpGs}$ 8-12. Therefore, $T F F 2$ mRNA expression levels are inversely related to $T F F 2$ promoter methylation in gastric neoplasia. To examine the ability of TFF2 methylation to discriminate between normal and gastric cancer tissues, we performed a 2-dimensional hierarchical cluster analysis using methylation ratio values from 8 of the $12 \mathrm{CpG}$ units in the TFF2 promoter (Figure $1 D$ ). The tissue specimens form 4 major clusters that separate normal antrum almost entirely from the gastric cancers. Of 28 cancers, only 3 are clustered with normal antrum, whereas none of the normal antrum tissues cluster with the cancers. Consistent with TFF2 mRNA data, gastritis and IM are not distinguished by TFF2 methylation levels but are collectively represented by 2 distinct clusters that cannot be classified as either normal or cancer. Our results indicate that $T F F 2$ promoter methylation is induced by $H$ pylori infection, does not increase additionally in IM, but does increase significantly thereafter in established tumors in late disease. To confirm that TFF2 silencing requires DNA methylation, we treated 2 human gastric cancer cell lines, AGS and MKN28, with the DNA methyltransferase inhibitor $5^{\prime}$-Aza-dC. Both cell lines cells show extremely low $T F F 2$ mRNA levels (Figure $2 A$ ) and very high $T F F 2$ promoter methylation levels compared with normal stomach (Figure $2 B$ ). $T F F 2$ expression was strongly up-regulated in AGS and MKN28 cells treated with $10 \mu \mathrm{mol} / \mathrm{L} 5^{\prime}$-Aza-dC for 72 hours compared to untreated controls (Figure $2 C$ ). These results argue strongly that the TFF2 promoter is silenced by DNA methylation in gastric cancer cells.

\section{Accelerated Tumor Growth in Tff2-Deficient Murine Gastric Cancer}

To determine the role of Tff 2 in gastric tumor progression, in particular to recapitulate the likely functional impact of $T F F 2$ silencing by promoter methylation in human gastric cancer, we compared antral tumor growth between $g p 130^{\mathrm{F} / \mathrm{F}}$ mice carrying wild-type or Tff2-null alleles (Figure $3 A$ ). Macroscopic morphometric analysis revealed that antral tumors in 6-week-old $g p 130^{\mathrm{F} / \mathrm{F}} / T f f 2^{-1-}$ compound mutant mice were more than double the size (105 $\pm 2.2 \mathrm{~mm}^{2}$ ) of $g p 130^{\mathrm{F} / \mathrm{F}}$ single mutant controls $\left(48 \pm 17 \mathrm{~mm}^{2}\right.$ ) (Figure $3 B$ ), and, by 12 weeks, $g p 130^{\mathrm{F} / \mathrm{F}} / \mathrm{Tff}^{-/-}$tumors were $35 \%$ larger than tumors of $g p 130^{\mathrm{F} / \mathrm{F}}$ single mutant and gp $130^{\mathrm{F} / \mathrm{F}} / \mathrm{Tff} 2^{+/-}$heterozygous null controls $\left(154 \pm 14 \mathrm{~mm}^{2}, 103 \pm 68 \mathrm{~mm}^{2}\right.$, and $95 \pm 92$ $\mathrm{mm}^{2}$, respectively) (Figure $3 B$ ). Microscopic analysis of antral tumor area at 12 weeks confirmed the increase in tumor size in $g p 130^{\mathrm{F} / \mathrm{F}} / T f f 2^{-/}$mice $\left(0.53 \pm 0.03 \mathrm{~mm}^{2}\right)$ compared with $g p 130^{\mathrm{F} / \mathrm{F}}\left(0.41 \pm 0.01 \mathrm{~mm}^{2}\right)$ and $g p 130^{\mathrm{F} / \mathrm{F}} / T f f 2^{+/-}$littermate controls $\left(0.41 \pm 0.04 \mathrm{~mm}^{2}\right)$ (Figure $3 C$ ). Consistent with these observations, mean antral gland height, cell number per antral gland, and Ki-67-positive cells (Figure $3 D$ ) were all increased in $g p 130^{\mathrm{F} / \mathrm{F}} / T f f 2^{-/-}$ antral tumors compared with $g p 130^{\mathrm{F} / \mathrm{F}}$ controls. No difference in apoptotic cell number was observed between $g p 130^{\mathrm{F} / \mathrm{F}} / T f f 2^{-/-}$and $g p 130^{\mathrm{F} / \mathrm{F}}$ antral tumors (Figure $3 E$ ), thus excluding decreased apoptosis as a mechanism for the accelerated tumor growth. In addition, expression of the gastric endocrine regulators gastrin and somatostatin were substantially reduced in $g p 130^{\mathrm{F} / \mathrm{F}} / T f f 2^{-/-}$mice compared with $g p 130^{\mathrm{F} / \mathrm{F}}$ controls (Figure $3 F$ ) indicating that increased tumor growth occurs under hypogastrinemic conditions. We conclude that antral tumor growth is accelerated in $g p 130^{\mathrm{F} / \mathrm{F}} / \mathrm{Tff} 2^{-/-}$mice, independently of apoptosis or gastrin, suggesting that $T f f 2$ negatively regulates gastric tumor progression.

\section{Accelerated Tumorigenesis in $g p 130^{F / F} / T_{f f 2}{ }^{-/-}$Mice Is Independent of Signal Transducer and Activator of Transcription 3 but Correlated With Decreased Tumor Suppressor Gene Expression}

Tumorigenesis in $g p 130^{\mathrm{F} / \mathrm{F}}$ mice is due to hyperactivation of the signal transducer and activator of transcription (Stat) 3 and reduced Tff1 TSG expression downstream of disrupted Shp2-ras-Erk/Ap1 signalling. ${ }^{11,32} \mathrm{We}$ found no difference in phosphorylated Stat3 or extracellular signal-regulated kinase (Erk) protein levels between $g p 130^{\mathrm{F} / \mathrm{F}} / T_{f f} 2^{-/-}$and $g p 130^{\mathrm{F} / \mathrm{F}}$ antrum (Supplementary Figure 2). Therefore, increased tumor growth in the 
absence of functional Tff 2 is independent of gastric gp130 signalling. By contrast, Tff1 protein (Figure $4 A$ ) and mRNA expression (Figure $4 B$ ) were significantly reduced in $g p 130^{\mathrm{F} / \mathrm{F}} / T f f 2^{-/-}$antral tumors compared with $g p 130^{\mathrm{F} / \mathrm{F}}$. We also examined the recently described gastric TSGs Gastrokine (Gkn) $1^{33}$ and $G k n 2^{34}$ and, similar to Tffl, found that the mRNA expression of both was more substantially reduced in the antrum of $g p 130^{\mathrm{F} / \mathrm{F}} / T f f 2^{-/-}$ mice compared with $g p 130^{\mathrm{F} / \mathrm{F}}$ controls (Figure $4 B$ ). Increased tumor growth in $g p 130^{\mathrm{F} / \mathrm{F}} /$ $T f f 2^{-/-}$mice is therefore independent of gp130 signalling via Stat3, but correlates with reduced expression of gastric TSGs: Tffl, Gknl, and Gkn2.

To substantiate further the impact of TFF2 on tumor growth and regulation of gastric TSGs, we examined proliferation and apoptosis in AGS cells treated with rhTFF2. Treatment with rhTFF2 slowed the growth of AGS cells by $25 \% \pm 4.3 \%(P<.05)$ after 48 hours compared with mock-treated cells (Figure $4 C$ ) and was dose dependent (Supplementary Figure 3). Apoptosis was unchanged between rhTFF2-treated cells and controls (Figure 4D), confirming our in vivo observation that Tff2 inhibits proliferation of gastric epithelial cells without affecting programmed cell death. We hypothesized that altered TSG expression accounts for the observed rhTFF2-mediated growth inhibition of AGS cells. Consistent with this, TFF1 expression was increased (fold change: $1.22 \pm 0.06, P<.05$ ) in rhTFF2 treated AGS cells (Figure $4 E$ ). Intriguingly, $T F F 2$ expression (fold change: $1.3 \pm 0.1, P<.05$ ) was also increased with rhTFF2 treatment, suggesting the existence of a positive feedback mechanism on $T F F 2$ transcription (Figure $4 E$ ).

\section{Th1 Polarized Immune Response in $g p 130^{F / F} / T_{f f 2}{ }^{-/-}$Antral Tumors}

Tumors in $g p 130^{\mathrm{F} / \mathrm{F}}$ mice are associated with extensive inflammation. Therefore, we next examined inflammatory mediators associated with $g p 130^{\mathrm{F} / \mathrm{F}} / T f f 2^{-/}$compound mutant tumors. We observed increased leukocyte infiltration in $g p 130^{\mathrm{F} / \mathrm{F}} / \mathrm{Tff}^{-/-}$compared with $g p 130^{\mathrm{F} / \mathrm{F}}$ mice (Figure $5 A$ and $B$ ), although numbers of activated macrophages (F4/80 positive) and neutrophils (myeloperoxidase [MPO] positive) were not significantly different (Figure 5C). Inflammatory leukocytes were mainly confined to desmin-positive lamina propria at the luminal margin of the epithelium (data not shown). In agreement with increased immunocyte infiltration, we observed a Th type 1 polarized immune response with significantly increased expression of the proinflammatory cytokines interleukin (IL)-la, $I L-1 \beta$, and interferon $(I F N)-\gamma$ in $g p 130^{\mathrm{F} / \mathrm{F}} / T f f 2^{-/-}$antral tumors compared with $g p 130^{\mathrm{F} / \mathrm{F}}$ controls (Figure $5 D$ ). We observed a concomitant decrease in the expression of the Th2 cytokine $I L-13$, with $I L-4$ also trending to decrease (Figure $5 E$ ). Thus, ablation of Tff2 in the context of gastric tumorigenesis results in a Th1 polarized response that may contribute directly to tumor progression by permitting increased leukocyte infiltration.

\section{Increased Fundic Atrophy in $g p 130^{F / F} / T_{f f 2}-1-$ Mice}

Histologic analysis revealed significant glandular atrophy in the fundus of 12-week $g p 130^{\mathrm{F} / \mathrm{F}} / T f f 2^{-l-}$ compared with wild-type and $g p 130^{\mathrm{F} / \mathrm{F}}$ mice (Figure $6 \mathrm{~A}$ and $\mathrm{B}$ ). To characterize the cellular composition of the fundus in $g p 130^{\mathrm{F} / \mathrm{F}} / T f f 2^{-/-}$mice, sections were stained for neutral and acidic mucins (AB/PAS; surface mucus and MNCs), Tff2, Griffonia simplicifolia lectin II (GSII) (MNCs), and intrinsic factor (chief cells). $\mathrm{H}^{+} \mathrm{K}^{+}$ATPase mRNA (parietal cells) was quantified by QRT-PCR. In $g p 130^{\mathrm{F} / \mathrm{F}} / \mathrm{Tff}^{-/-}$and to a lesser extent in gp $130^{\mathrm{F} / \mathrm{F}} / T f f 2^{+/-}$mice, the fundic mucosa consisted predominantly of a GSII and AB/PASpositive MNC-like population and was almost entirely devoid of parietal and chief cells (Figure $6 A-C$ ). Therefore, genetic ablation of Tff2 in the context of pre-existing gastric pathology accelerates the loss of differentiated epithelial cell types leading to profound glandular atrophy. 


\section{H pylori Induces Tff2 Promoter Methylation After Chronic Infection in Mice}

To show definitively that $H$ pylori infection can induce $T f f 2$ promoter methylation, we next analysed stomachs from wild-type (C57BL/6) mice experimentally infected with the mouseadapted $H$ pylori SS1 strain for 12 and 15 months. Tff 2 expression was reduced in $H$ pylori 12-month postinfection (MPI) stomach (Figure 7A), whereas Tff2 promoter methylation was markedly increased at $12 \mathrm{MPI}$ (and $15 \mathrm{MPI}$ ) compared with age-matched noninfected controls (Figure $7 B$ ). These observations were supported by hierarchical cluster analysis which effectively discriminated $H$ pylori-infected mice from noninfected mice on the basis of Tff2 methylation profiles (Figure 7C). Collectively, these results show that chronic $H$ pylori infection directly induces Tff2 promoter methylation in vivo. Because the progression of gastric pathology is clearly accelerated in $g p 130^{\mathrm{F} / \mathrm{F}} / \mathrm{Tff}^{-/-}$mice, and $\mathrm{H}$ pylori infection leads to gastric Tff2-deficiency via epigenetic silencing (Figure 7A-C), we also investigated whether short-term ( 3 months) $H$ pylori infection in $g p 130^{\mathrm{F} / \mathrm{F}}$ mice can phenocopy the effects of genetic Tff2 deficiency by augmenting Tff2 promoter methylation. We observed no effect of the $g p 130^{\mathrm{F} / \mathrm{F}}$ mutation, H pylori, or their combined effect on Tff2 expression or methylation (Supplementary Figure 4) in antral stomach after 3 months of infection.

\section{Discussion}

We have established TFF2 epigenetic silencing, by promoter methylation, as a novel paradigm for loss of TFF2 expression in human intestinal-type gastric cancer ${ }^{35,36}$ and following experimental $H$ pylori infection in the mouse stomach. We also assessed Tff2 function in the context of mouse gastric tumor growth. Disruption of Tff2 in $g p 130^{\mathrm{F} / \mathrm{F}} /$ $T f f 2^{-1-}$ mice produced a polarized immune response, with subdued Th2 and exacerbated Th1-type inflammation. Tff2 deficiency in 6- and 12-week $g p 130^{\mathrm{F} / \mathrm{F}} / T f f 2^{-/-}$mice caused larger tumors compared with $g p 130^{\mathrm{F} / \mathrm{F}}$ mice because of increased proliferation and accumulation of mucus cells without affecting apoptosis. This demonstrates a novel function for Tff 2 in restraining tumorigenesis and acting as a TSG in the stomach (Supplementary Figure 5). Concordantly, development of gastric neoplasia is accelerated in Tff2-deficient mice compared with wild-type littermates after $H$ pylori infection. ${ }^{26}$

Whereas tumorigenesis in $g p 130^{\mathrm{F} / \mathrm{F}}$ mice is attributed to dysregulated gp130 signalling and repression of TffI $1{ }^{11}$ genetic ablation of Tff 2 conferred no additional dysregulation upon gp130 signalling via Stat3 or Shp2-ras-Erk/Ap1 pathways. However, Tff2 deficiency led to reduced expression of Tffl and putative TSGs, Gknl, and Gkn2. These 2 gastrokines are emerging as important endogenous regulators of gastric homeostasis and show profound loss of expression in $\mathrm{H}$ pylori infection, aspirin ingestion, ${ }^{37,38}$ and neoplastic progression. ${ }^{39}$ Thus, TFF2 is a likely upstream regulator of gastrokine gene expression, and its inhibition may promote tumor growth because of loss of anti-proliferative gastrokine and TFF1 genes. Additionally, human GKN2 protein exists predominantly as a heterodimer with TFF1 ${ }^{40}$ thus attenuated expression of either protein may potentiate their combined loss of function.

Tff2 deficiency in $g p 130^{\mathrm{F} / \mathrm{F}} / T f f 2^{-/-}$mice led to reduced $T f f 1$ expression. This finding provides a mechanism for increased proliferation because $T F F 1$ has previously been shown to inhibit the growth of the human gastric cancer AGS cell line. ${ }^{15}$ Here we have shown that exogenous TFF2 peptide inhibits the growth of AGS cells without affecting apoptosis. Treatment with rhTFF 2 increased $T F F 1$ and $T F F 2$ mRNA expression in cell lines, consistent with reported cross- and autoregulatory functions for TFF $2 .{ }^{41}$ Moreover, downregulation of both $T F F 1$ and $T F F 2$ expression frequently occurs in gastric cancer, ${ }^{35,36}$ consistent with a tumor suppressor function.

$T F F 1$ and TFF2 play critical roles in maintaining mucosal integrity, ${ }^{42}$ and combined functional loss likely compromises the gastric mucosa, permitting increased inflammation 
and damage while subduing repair processes. In this context, compound $g p 130^{\mathrm{F} / \mathrm{F}} / T f f 2^{-/-}$ mice displayed pervasive fundic atrophy by 12 weeks of age with significant loss of parietal and chief cell lineages and accumulation of undifferentiated GSII-positive MNC-like cells. Similarly, fundic atrophy is accelerated in Tff2-deficient mice chronically infected with Helicobacter species. ${ }^{20,26}$

Tumorigenesis in $g p 130^{\mathrm{F} / \mathrm{F}} / T f f 2^{-/-}$mice was associated with augmented Th1 cytokine release and attenuated Th2 cytokine expression, particularly $I L-13$. Th1 cytokines, in particular IL-1 $\beta$, promote mucosal inflammation, inhibit gastric acid secretion ${ }^{43}$ and induce fundic atrophy leading to gastric adenocarcinoma. ${ }^{44}$ Our data suggest that Tff2 may modulate and prevent imbalanced levels of Th1 and Th2 cytokines leading to mucosal destruction and disrepair. It is unknown whether $T F F 2$ directly regulates inflammatory cytokines; however, these results highlight the important homeostatic role for $T F F 2$ in the normal gastric mucosa. TFF2 loss after $H$ pylori infection provides a mechanism by which the bacterium may modulate the local immune response.

Expression of the hormones, gastrin and somatostatin, required for normal gastric mucosal development, and the former for parietal cell activation, ${ }^{45}$ was almost completely ablated in gp $130^{\mathrm{F} / \mathrm{F}} / T f f 2^{-/-}$tumors. Gastrin deficiency results in chronic atrophic gastritis and predisposition to tumors via IFN $\gamma / \mathrm{STAT} 3$ activity, ${ }^{46}$ thus decreased gastrin and somatostatin may contribute to the observed fundic atrophy. Additionally, because gastrin is a direct transcriptional regulator of $T f f 1,{ }^{47}$ its profound suppression in $g p 130^{\mathrm{F} / \mathrm{F}} / T f f 2^{-/-}$mice may also contribute to loss of $T f f I$ expression, independent but in concert with the effects of Tff 2 .

Quantitative analysis of normal human antral stomach, $H$ pylori-dependent gastritis, intestinal metaplasia, and tumor cohorts revealed progressive loss of $T F F 2$ expression during gastric cancer development and concomitant gain of promoter methylation, particularly at $\mathrm{CpG}$ dinucleotides overlapping the transcription start site. This is the first description of $T F F 2$ promoter methylation in precancerous or cancerous stomach, supporting the notion that TFF2 is a TSG targeted by epigenetic silencing. Whereas we believe that promoter methylation represents a principle means of TFF2 silencing, it is also possible that metaplasic induction leads to antral mucus cell loss and depletion of the source of TFF2 synthesis. Increased tumor growth in $g p 130^{\mathrm{F} / \mathrm{F}} / \mathrm{Tff}^{-l-}$ mice clearly illustrates how perturbed TFF 2 expression might influence the rate of tumor progression in human gastric cancer. This is supported by our in vitro studies in which genome demethylation in AGS and MKN28 gastric cancer cell lines restores TFF2 transcription, and recombinant TFF2 treatment in AGS cells activates TFF1 transcription and inhibits cell proliferation.

Our human and mouse data show that $T F F 2$ methylation is likely initiated during $H$ pylori infection, although the mechanism is unclear. This may not be a direct function of the bacterium itself but more likely arises from infection-dependent inflammation, in particular the activity of proinflammatory cytokines such as IL- $1 \beta$, the expression of which is inversely correlated with that of TFF2. IL- $1 \beta$ expression is up-regulated during $H$ pylori infection ${ }^{48}$ and reportedly induces nitric oxide production, which stimulates DNA methyltransferases responsible for inappropriate hypermethylation and transcriptional gene silencing. ${ }^{49}$ Thus, increased IL- $1 \beta$ release may indirectly mediate $T F F 2$ epigenetic silencing in human gastric cancer.

Inappropriate epigenetic silencing is one of the earliest detectable molecular defects in gastric tumorigenesis. ${ }^{50}$ We demonstrate that $T F F 2$ promoter methylation effectively discriminates $\mathrm{H}$ pylori-positive gastritis/intestinal metaplasia, gastric cancer, and diseasefree control tissue thereby warranting further evaluation of its diagnostic potential. This also raises the possibility of future clinical application of nontoxic DNA methylation inhibitors 
such as $5^{\prime}$-Aza-C to reverse the inappropriate gene silencing of key gastric regulator genes. DNA methylation profiles are far more stable than mRNA markers and, as exemplified by our analysis of $T F F 2$, provide a robust surrogate for transcriptional silencing during the formative stages of tumorigenesis. Determination of gastric TFF2 methylation profiles may provide a novel approach for early intervention in gastric adenocarcinoma, a disease in which late diagnosis continues to present a major therapeutic challenge. In summary, we demonstrate that $T F F 2$ expression is epigenetically silenced during the progression to human intestinal-type gastric cancer by promoter hypermethylation. Taken together with our mouse genetic analysis, we conclude that TFF2 functions as a novel stomach-specific and epigenetically regulated tumor suppressor gene.

\section{Supplementary Material}

Refer to Web version on PubMed Central for supplementary material.

\section{Acknowledgments}

The authors thank Matthias Ernst (Ludwig Institute for Cancer Research, Melbourne) for $g p 130^{\mathrm{F} / \mathrm{F}}$ knock-in mice, Nick Wong (Murdoch Children's Research Institute, Melbourne) for advice with methylation data cleaning and hierarchical cluster analysis, and Lars Thim (Novo Nordisk) for rhTFF2.

Funding

Supported by the National Health and Medical Research Council, Australia.

\section{Abbreviations used in this paper}

$\begin{array}{ll}\text { 5'-Aza-C } & 5^{\prime} \text {-aza- }{ }^{\prime} \text {-deoxycytidine } \\ \text { AB/PAS } & \text { alcian blue periodic acid-Schiff } \\ \text { Erk } & \text { extracellular signal-regulated kinase } \\ \text { IFN } & \text { interferon } \\ \text { IL } & \text { interleukin } \\ \text { IM } & \text { intestinal metaplasia } \\ \text { MNC } & \text { mucus neck cell } \\ \text { MPI } & \text { month postinfection } \\ \text { mRNA } & \text { messenger RNA } \\ \text { PCR } & \text { polymerase chain reaction } \\ \text { QRT-PCR } & \text { quantitative reverse-transcription polymerase chain reaction } \\ \text { rh } & \text { recombinant human } \\ \text { SPEM } & \text { spasmolytic polypeptide-expressing metaplasia } \\ \text { Stat } & \text { signal transducer and activator of transcription } \\ \text { TFF } & \text { Trefoil factor } \\ \text { TSG } & \text { tumor suppressor gene }\end{array}$

\section{References}

1. Wright NA, Hoffmann W, Otto WR, et al. Rolling in the clover: trefoil factor family (TFF)-domain peptides, cell migration and cancer. FEBS Lett. 1997; 408:121-123. [PubMed: 9187350] 
2. Lefebvre O, Wolf C, Kedinger M, et al. The mouse one P-domain (pS2) and two P-domain (mSP) genes exhibit distinct patterns of expression. J Cell Biol. 1993; 122:191-198. [PubMed: 8314841]

3. Taupin DR, Pang KC, Green SP, et al. The trefoil peptides spasmolytic polypeptide and intestinal trefoil factor are major secretory products of the rat gut. Peptides. 1995; 16:1001-1005. [PubMed: 8532580]

4. Suemori S, Lynch-Devaney K, Podolsky DK. Identification and characterization of rat intestinal trefoil factor: tissue- and cell-specific member of the trefoil protein family. Proc Natl Acad Sci U S A. 1991; 88:11017-11021. [PubMed: 1763017]

5. Kindon H, Pothoulakis C, Thim L, et al. Trefoil peptide protection of intestinal epithelial barrier function: cooperative interaction with mucin glycoprotein. Gastroenterology. 1995; 109:516-523. [PubMed: 7615201]

6. Dignass A, Lynch-Devaney K, Kindon H, et al. Trefoil peptides promote epithelial migration through a transforming growth factor $\beta$-independent pathway. J Clin Invest. 1994; 94:376-383. [PubMed: 8040278]

7. Playford RJ, Marchbank T, Chinery R, et al. Human spasmolytic polypeptide is a cytoprotective agent that stimulates cell migration. Gastroenterology. 1995; 108:108-116. [PubMed: 7806031]

8. Familari M, Cook GA, Taupin DR, et al. Trefoil peptides are early markers of gastrointestinal maturation in the rat. Int J Dev Biol. 1998; 42:783-789. [PubMed: 9727834]

9. Bossenmeyer-Pourie C, Kannan R, Ribieras S, et al. The trefoil factor 1 participates in gastrointestinal cell differentiation by delaying G1-S phase transition and reducing apoptosis. J Cell Biol. 2002; 157:761-770. [PubMed: 12034770]

10. Lefebvre O, Chenard MP, Masson R, et al. Gastric mucosa abnormalities and tumorigenesis in mice lacking the pS2 trefoil protein. Science. 1996; 274:259-262. [PubMed: 8824193]

11. Tebbutt NC, Giraud AS, Inglese M, et al. Reciprocal regulation of gastrointestinal homeostasis by SHP2 and STAT-mediated trefoil gene activation in gp130 mutant mice. Nat Med. 2002; 8:10891997. [PubMed: 12219085]

12. Boussioutas A, Li H, Liu J, et al. Distinctive patterns of gene expression in premalignant gastric mucosa and gastric cancer. Cancer Res. 2003; 63:2569-2577. [PubMed: 12750281]

13. Carvalho R, Kayademir T, Soares P, et al. Loss of heterozygosity and promoter methylation, but not mutation, may underlie loss of TFF1 in gastric carcinoma. Lab Invest. 2002; 82:1319-1326. [PubMed: 12379766]

14. Baus-Loncar M, Giraud AS. Multiple regulatory pathways for trefoil factor (TFF) genes. Cell Mol Life Sci. 2005; 62:2921-2931. [PubMed: 16374580]

15. Calnan DP, Westley BR, May FE, et al. The trefoil peptide TFF1 inhibits the growth of the human gastric adenocarcinoma cell line AGS. J Pathol. 1999; 188:312-317. [PubMed: 10419601]

16. Karam SM, Tomasetto C, Rio MC. Trefoil factor 1 is required for the commitment programme of mouse oxyntic epithelial progenitors. Gut. 2004; 53:1408-1415. [PubMed: 15361486]

17. Wright NA, Poulsom R, Stamp G, et al. Trefoil peptide gene expression in gastrointestinal epithelial cells in inflammatory bowel disease. Gastroenterology. 1993; 104:12-20. [PubMed: 8419234]

18. Farrell JJ, Taupin D, Koh TJ, et al. TFF2/SP-deficient mice show decreased gastric proliferation, increased acid secretion, and increased susceptibility to NSAID injury. J Clin Invest. 2002; 109:193-204. [PubMed: 11805131]

19. Cook GA, Thim L, Yeomans ND, et al. Oral human spasmolytic polypeptide protects against aspirin-induced gastric injury in rats. J Gastroenterol Hepatol. 1998; 13:363-370. [PubMed: 9641298]

20. Wang TC, Goldenring JR, Dangler C, et al. Mice lacking secretory phospholipase A2 show altered apoptosis and differentiation with Helicobacter felis infection. Gastroenterology. 1998; 114:675689. [PubMed: 9516388]

21. Nomura S, Yamaguchi H, Ogawa M, et al. Alterations in gastric mucosal lineages induced by acute oxyntic atrophy in wild-type and gastrin-deficient mice. Am J Physiol Gastrointest Liver Physiol. 2005; 288:G362-G375. [PubMed: 15647607]

22. Schmidt PH, Lee JR, Joshi V, et al. Identification of a metaplastic cell lineage associated with human gastric adenocarcinoma. Lab Invest. 1999; 79:639-646. [PubMed: 10378506] 
23. Ogawa M, Nomura S, Varro A, et al. Altered metaplastic response of waved-2 EGF receptor mutant mice to acute oxyntic atrophy. Am J Physiol Gastrointest Liver Physiol. 2006; 290:G793G804. [PubMed: 16306133]

24. Baus-Loncar M, Schmid J, Lalaniel N, et al. Trefoil factor 2 (TFF2) deficiency in murine digestive tract influences the immune system. Cell Physiol Biochem. 2005; 16:31-42. [PubMed: 16121031]

25. Kurt-Jones EA, Cao L, Sandor F, et al. Trefoil family factor 2 is expressed in murine gastric and immune cells and controls both gastrointestinal inflammation and systemic immune responses. Infect Immun. 2007; 75:471-480. [PubMed: 17101660]

26. Fox JG, Rogers AB, Whary MT, et al. Accelerated progression of gastritis to dysplasia in the pyloric antrum of TFF2 ${ }^{-/-}$C57BL6 x Sv129 Helicobacter pylori-infected mice. Am J Pathol. 2007; 171:1520-1528. [PubMed: 17982128]

27. Judd LM, Alderman BM, Howlett M, et al. Gastric cancer development in mice lacking the SHP2 binding site on the IL-6 family co-receptor gp130. Gastroenterology. 2004; 126:196-207. [PubMed: 14699500]

28. Jackson CB, Judd LM, Menheniott TR, et al. Augmented gp130-mediated cytokine signalling accompanies human gastric cancer progression. J Pathol. 2007; 213:140-151. [PubMed: 17724739]

29. Fox BJS, Charles A, Dangler MT, et al. Germ-line p53-targeted disruption inhibits Helicobacterinduced premalignant lesions and invasive gastric carcinoma through down-regulation of Th1 proinflammatory responses. Cancer Res. 2002; 62:696-702. [PubMed: 11830522]

30. Coolen MW, Statham AL, Gardiner-Garden M, et al. Genomic profiling of CpG methylation and allelic specificity using quantitative high-throughput mass spectrometry: critical evaluation and improvements. Nucleic Acids Res. 2007; 35:e119. [PubMed: 17855397]

31. Giraud AS, Jackson C, Menheniott TR, et al. Differentiation of the gastric mucosa IV. Role of trefoil peptides and IL-6 cytokine family signaling in gastric homeostasis. Am J Physiol Gastrointest Liver Physiol. 2007; 292:G1-G5. [PubMed: 16935852]

32. Judd LM, Bredin K, Kalantzis A, et al. STAT3 activation regulates growth, inflammation, and vascularization in a mouse model of gastric tumorigenesis. Gastroenterology. 2006; 131:10731085. [PubMed: 17030178]

33. Martin TE, Powell CT, Wang Z, et al. A novel mitogenic protein that is highly expressed in cells of the gastric antrum mucosa. Am J Physiol Gastrointest Liver Physiol. 2003; 285:G332-G343. [PubMed: 12851218]

34. Akiyama Y, Watkins N, Suzuki H, et al. GATA-4 and GATA-5 transcription factor genes and potential downstream antitumor target genes are epigenetically silenced in colorectal and gastric cancer. Mol Cell Biol. 2003; 23:8429-8439. [PubMed: 14612389]

35. Leung WK, Yu J, Chan FK, et al. Expression of trefoil peptides (TFF1, TFF2, and TFF3) in gastric carcinomas, intestinal metaplasia, and non-neoplastic gastric tissues. J Pathol. 2002; 197:582-588. [PubMed: 12210076]

36. Shi SQ, Cai JT, Yang JM. Expression of trefoil factors 1 and 2 in precancerous condition and gastric cancer. World J Gastroenterol. 2006; 12:3119-3122. [PubMed: 16718800]

37. Martin G, Wex T, Treiber G, et al. Low-dose aspirin reduces the gene expression of gastrokine-1 in the antral mucosa of healthy subjects. Aliment Pharmacol Ther. 2008; 28:782-788. [PubMed: 19145733]

38. Resnick MB, Sabo E, Meitner PA, et al. Global analysis of the human gastric epithelial transcriptome altered by Helicobacter pylori eradication in vivo. Gut. 2006; 55:1717-1724. [PubMed: 16641130]

39. Moss SF, Lee JW, Sabo E, et al. Decreased expression of gastrokine 1 the trefoil factor interacting protein TFIZ1/GKN2 in gastric cancer: influence of tumor histology and relationship to prognosis. Clin Cancer Res. 2008; 14:4161-4167. [PubMed: 18593995]

40. Westley BR, Griffin SM, May FE. Interaction between TFF1, a gastric tumor suppressor trefoil protein, and TFIZ1, a brichos domain-containing protein with homology to SP-C. Biochemistry. 2005; 44:7967-7975. [PubMed: 15924415] 
41. Bulitta CJ, Fleming JV, Raychowdhury R, et al. Autoinduction of the trefoil factor 2 (TFF2) promoter requires an upstream cisacting element. Biochem Biophys Res Commun. 2002; 293:366-374. [PubMed: 12054609]

42. Taupin D, Podolsky DK. Trefoil factors: initiators of mucosal healing. Nat Rev Mol Cell Biol. 2003; 4:721-732. [PubMed: 14506475]

43. Wolfe MM, Nompleggi DJ. Cytokine inhibition of gastric acid secretion-a little goes a long way. Gastroenterology. 1992; 102:2177-2178. [PubMed: 1587446]

44. Tu S, Bhagat G, Cui G, et al. Overexpression of interleukin-1 $\beta$ induces gastric inflammation and cancer and mobilizes myeloid-derived suppressor cells in mice. Cancer Cell. 2008; 14:408-419. [PubMed: 18977329]

45. Dockray GJ, Varro A, Dimaline R, et al. The gastrins: their production and biological activities. Annu Rev Physiol. 2001; 63:119-139. [PubMed: 11181951]

46. Zavros Y, Eaton KA, Kang W, et al. Chronic gastritis in the hypochlorhydric gastrin-deficient mouse progresses to adenocarcinoma. Oncogene. 2005; 24:2354-2366. [PubMed: 15735748]

47. Khan ZE, Wang TC, Cui G, et al. Transcriptional regulation of the human trefoil factor, TFF1, by gastrin. Gastroenterology. 2003; 125:510-521. [PubMed: 12891554]

48. Persson C, Engstrand L, Nyren O, et al. Interleukin 1- $\beta$ gene polymorphisms and risk of gastric cancer in Sweden. Scand J Gastroenterol. 2009; 44:339-345. [PubMed: 19031173]

49. Hmadcha A, Bedoya FJ, Sobrino F, et al. Methylation-dependent gene silencing induced by interleukin $1 \beta$ via nitric oxide production. J Exp Med. 1999; 190:1595-1604. [PubMed: 10587350]

50. Kang GH, Lee HJ, Hwang KS, et al. Aberrant CpG island hypermethylation of chronic gastritis, in relation to aging, gender, intestinal metaplasia, and chronic inflammation. Am J Pathol. 2003; 163:1551-1556. [PubMed: 14507661] 

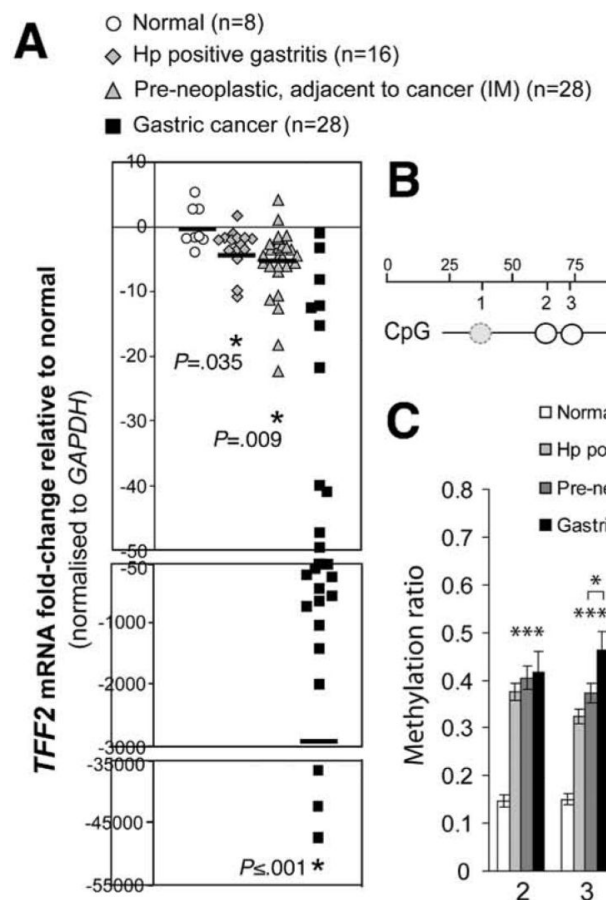

\section{B}

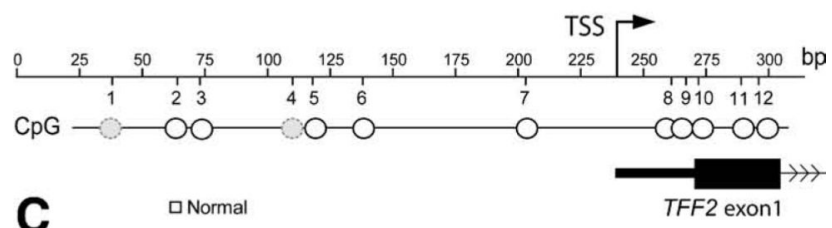

aHp positive gastritis

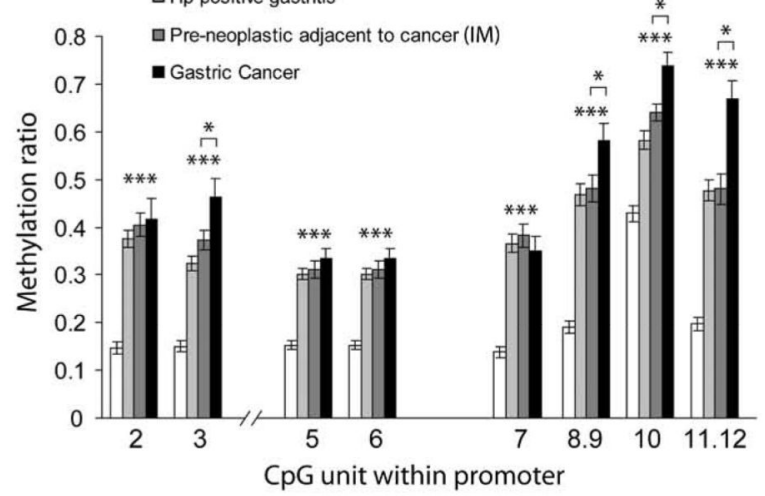

D

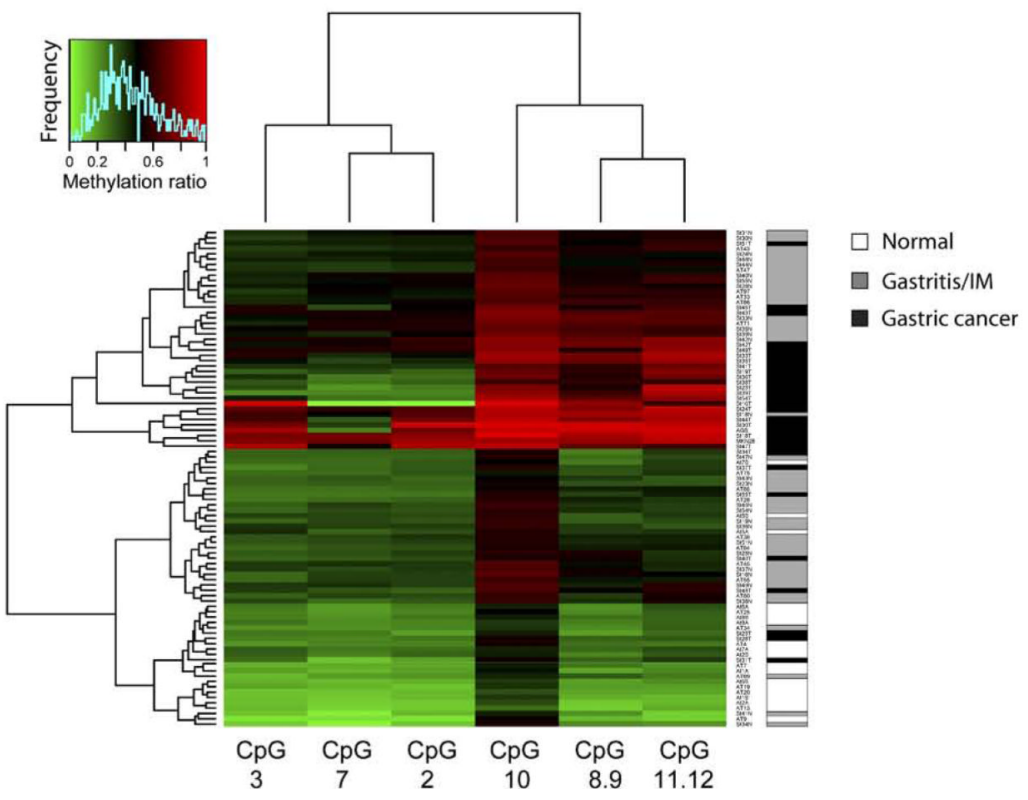

Figure 1.

Increased TFF2 promoter methylation correlates with loss of expression in gastric cancer. (A) QRT-PCR analysis of TFF2 messenger RNA (mRNA) levels in human gastric mucosal tissues ( $\mathrm{n}=91)$; graph shows mRNA fold-change relative to normal stomach; black bars show mean fold-change. Asterisks show statistical significance $(P<.05)$. (B) TFF2 promoter region scanned by EPITYPER methylation analysis. Wide black box shows coding regions; narrow black box shows 5' UTR: arrowheads show transcriptional orientation; TFF2 transcription start site (TSS); base pair (bp) positions are indicated; solid-line circles show CpGs covered by the analysis; broken-line circles show nonanalyzed CpGs. (C) EPITYPER 
DNA methylation analysis in human gastric mucosal tissues described in A. Bar graph shows mean CpG methylation ratios (levels). CpG units in pairs 8-9 and 11-12, respectively, are shown as combined averages (the constituent $\mathrm{CpG}$ units were not resolved by the EPITYPER assay). Asterisks show statistical significance $(P<.05)$. (D) Two-way hierarchical cluster analysis of TFF2 promoter methylation levels (columns) against human tissue samples (rows). Classification of the human gastric mucosal tissues is shown on the right: open boxes (normal stomach), shaded boxes (H pylori-positive gastritis/preneoplastic adjacent to cancer with IM), solid boxes (gastric cancer). CpG methylation ratios 0 (green) to 1.0 (red; see color key). Histogram shows $\mathrm{CpG} /$ methylation ratio frequency. 


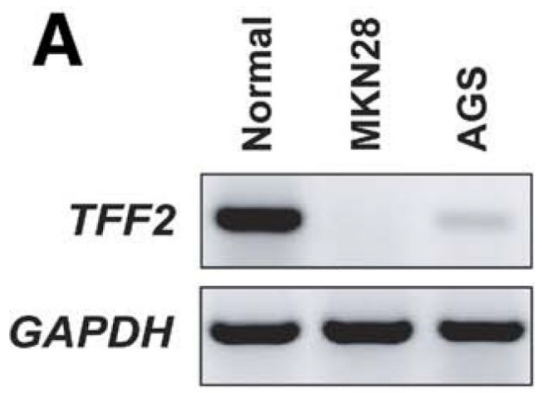

B

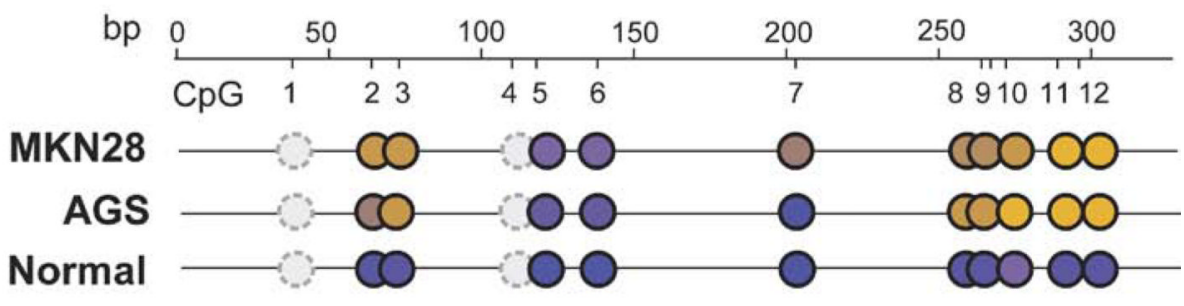

Methylation: $0 \% 0000000000100 \%$

C
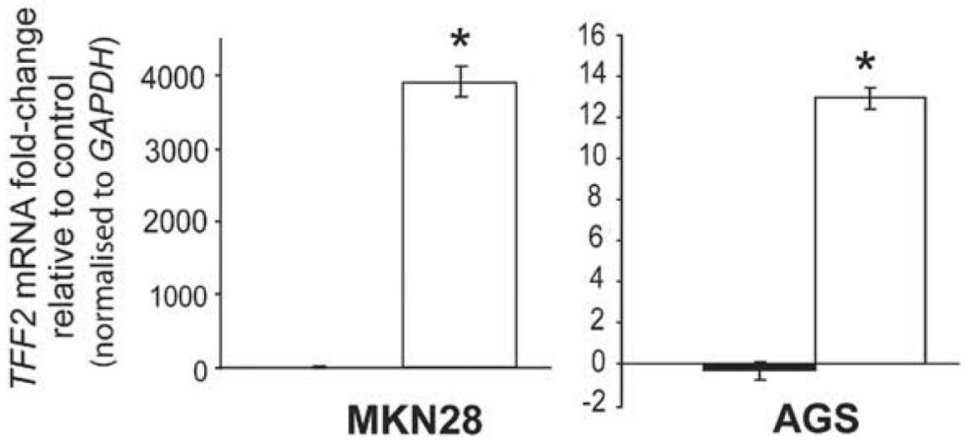

Control

5'Aza-dC

( $n=6 /$ group)

Figure 2.

TFF2 is re-expressed following genome demethylation. (A) Semiquantitative RT-PCR analysis of TFF2 messenger RNA (mRNA) expression in normal gastric antrum, MKN28 cells, and AGS cells. GAPDH demonstrates complementary DNA (cDNA) integrity. (B) EPITYPER analysis of TFF2 promoter methylation of samples shown in A. Epigrams show CpG methylation ratios: graded from blue ( 0 ; hypomethylated) to yellow ( 1 ; hypermethylated). Base pair ( $b p$ ) positions are indicated; solid circles show $\mathrm{CpGs}$ covered by the analysis; faded circles show nonanalyzed CpGs. (C) QRT-PCR analysis of TFF2 expression in MKN28 cells and AGS cells treated with $10 \mu \mathrm{mol} / \mathrm{L} 5^{\prime} \mathrm{Aza}-\mathrm{dC}$ for 72 hours compared with mock-treated controls $(\mathrm{n}=6)$. Histograms show mean mRNA fold-change relative to untreated control. Asterisks show statistical significance $(P<.05)$. 
A
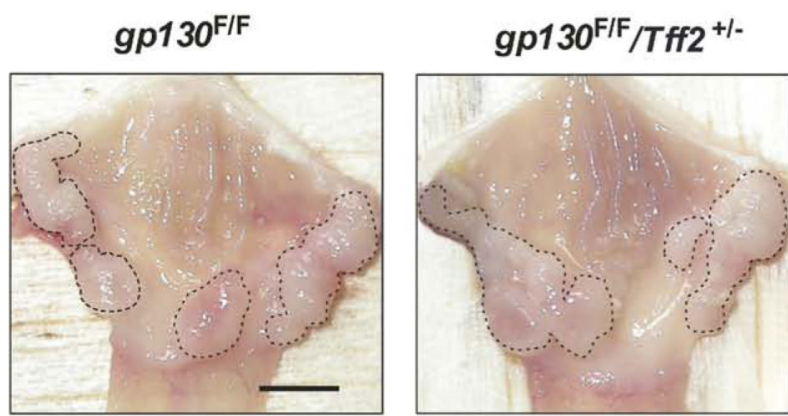

B

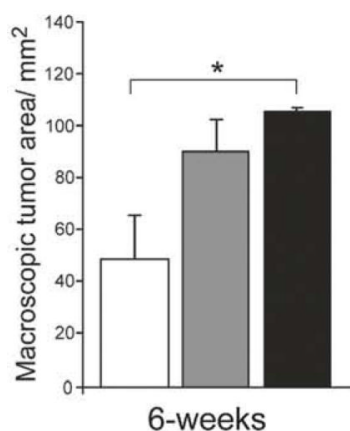

6-weeks

D
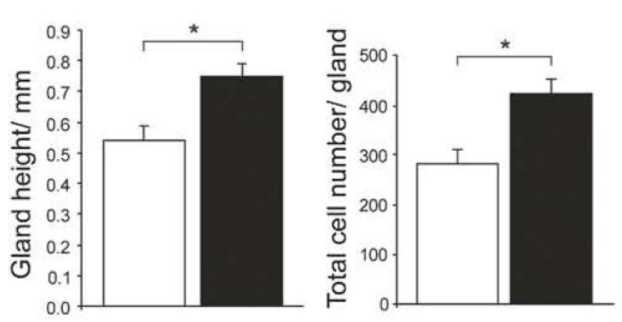

F

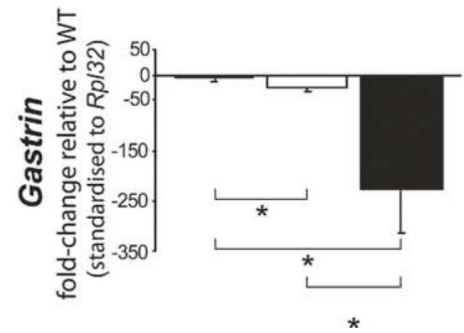

C
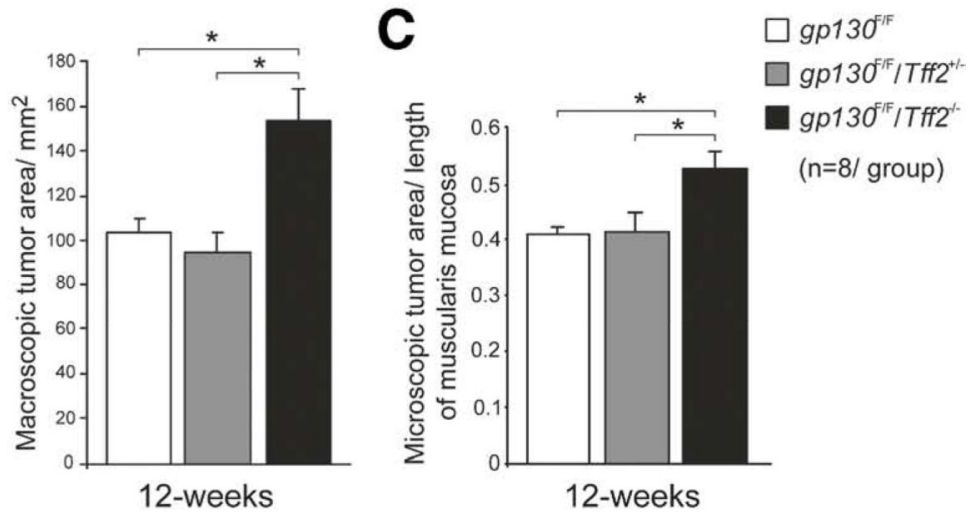

E
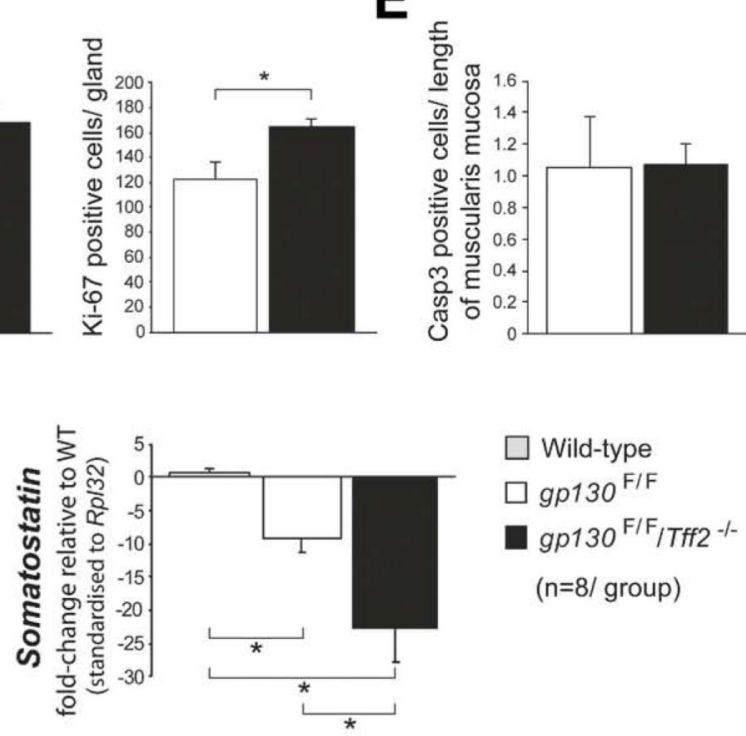

$\square$ Wild-type

$\square g p 130^{\mathrm{F} / \mathrm{F}}$

gp130 $\mathrm{F} / \mathrm{F} / \mathrm{Tff} 2^{-/}$

( $n=8 /$ group)

Figure 3.

Morphometric analysis of antral tumors in $g p 130^{\mathrm{F} / \mathrm{F}} / T f 2^{-/-}$mice. (A) Images of antral tumors in 12-week-old mice; tumor areas are defined with dotted outlines; scale bar shows 5 mm. (B) Macroscopic morphometric analysis of antral tumor area in 6- and 12-week-old mice. $(C)$ Microscopic morphometric analysis of tumor area (standardized to length of muscularis mucosa) in 12-week-old mice. $(D)$ Antral gland height; cell number per antral gland; proliferating cells by quantitative Ki-67 immunohistochemistry. $(E)$ Localization of apoptotic cells by quantitative activated caspase (casp) 3 immunohistochemistry. $(F)$ QRTPCR analysis of Gastrin and Somatostatin messenger RNA (mRNA) expression. 
Histograms show mean mRNA fold change relative to wild-type. Asterisks show statistical significance $(P<.05)$. 
A
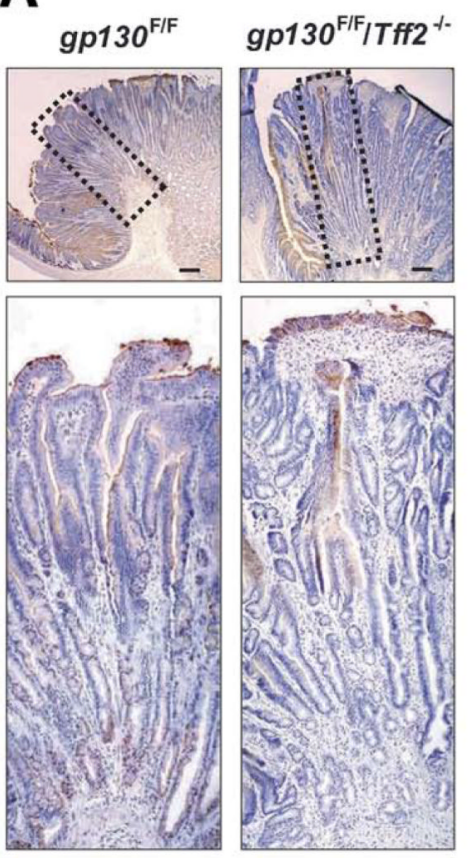

B
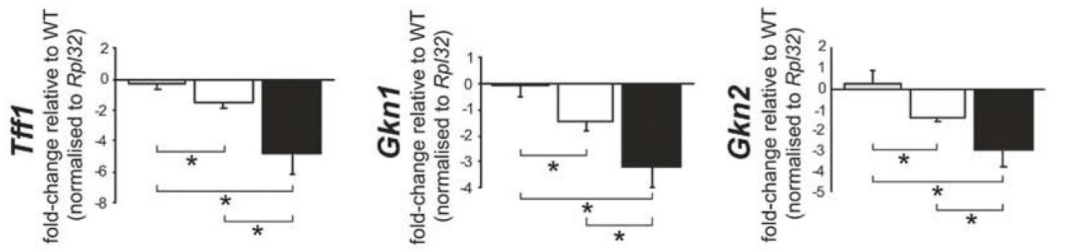

C

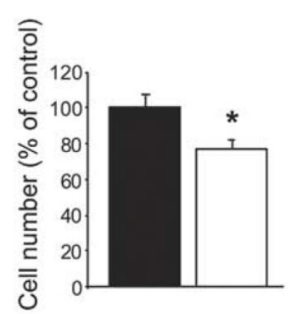

E

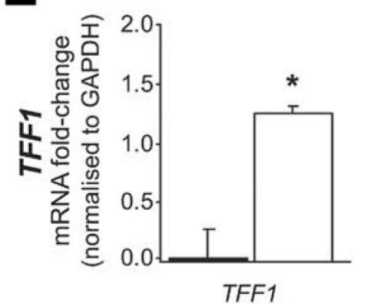

D

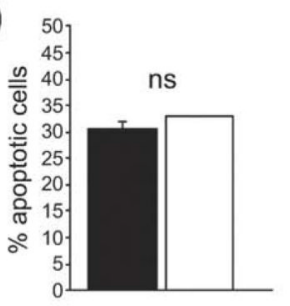

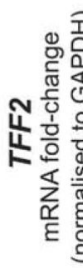

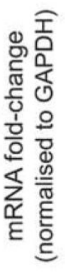

Wild-type $\square$ gp130 FiF

gp130 $\mathrm{FF} / \mathrm{Tff}^{\text {t* }}$

Figure 4.

Loss of gastric tumor suppressor gene expression in $g p 130^{\mathrm{F} / \mathrm{F}} / T f f 2^{-/-}$antral tumors. (A) Immunohistochemical localization of Tff1 in antral tumors. (B) QRT-PCR analysis of Tff1, $G k n 1$, and Gkn2. Histograms show mean messenger RNA (mRNA) fold change relative to wild type. $(C)$ Proliferation determined by viable cell counts in AGS cells following treatment with $50 \mu \mathrm{g} / \mathrm{mL}$ recombinant human (rh) TFF2 for 48 hours $(\mathrm{n}=20)$. (D) Apoptosis measured by Annexin V flow cytometry in AGS cells treated with $50 \mu \mathrm{g} / \mathrm{mL}$ rhTFF2 for 48 hours $(\mathrm{n}=5)$. (E) QRT-PCR analysis of TFF1 and TFF2 mRNA expression in AGS cells treated with $50 \mu \mathrm{g} / \mathrm{mL}$ rhTFF2 for 48 hours $(\mathrm{n}=6)$. Asterisks show statistical significance $(P<.05)$. 
A
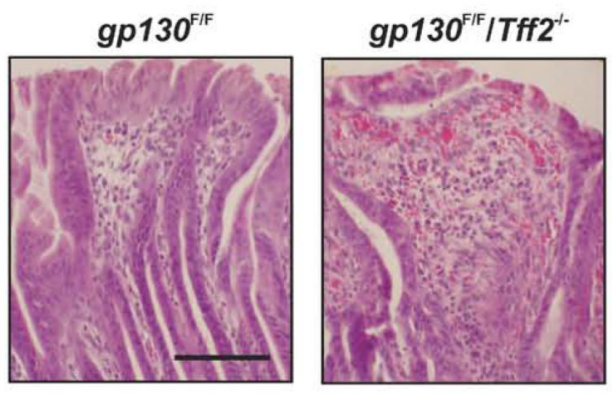

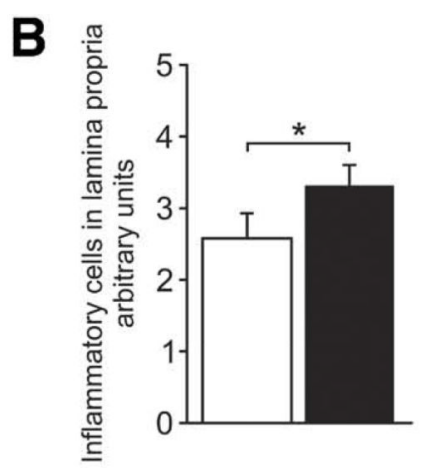

C
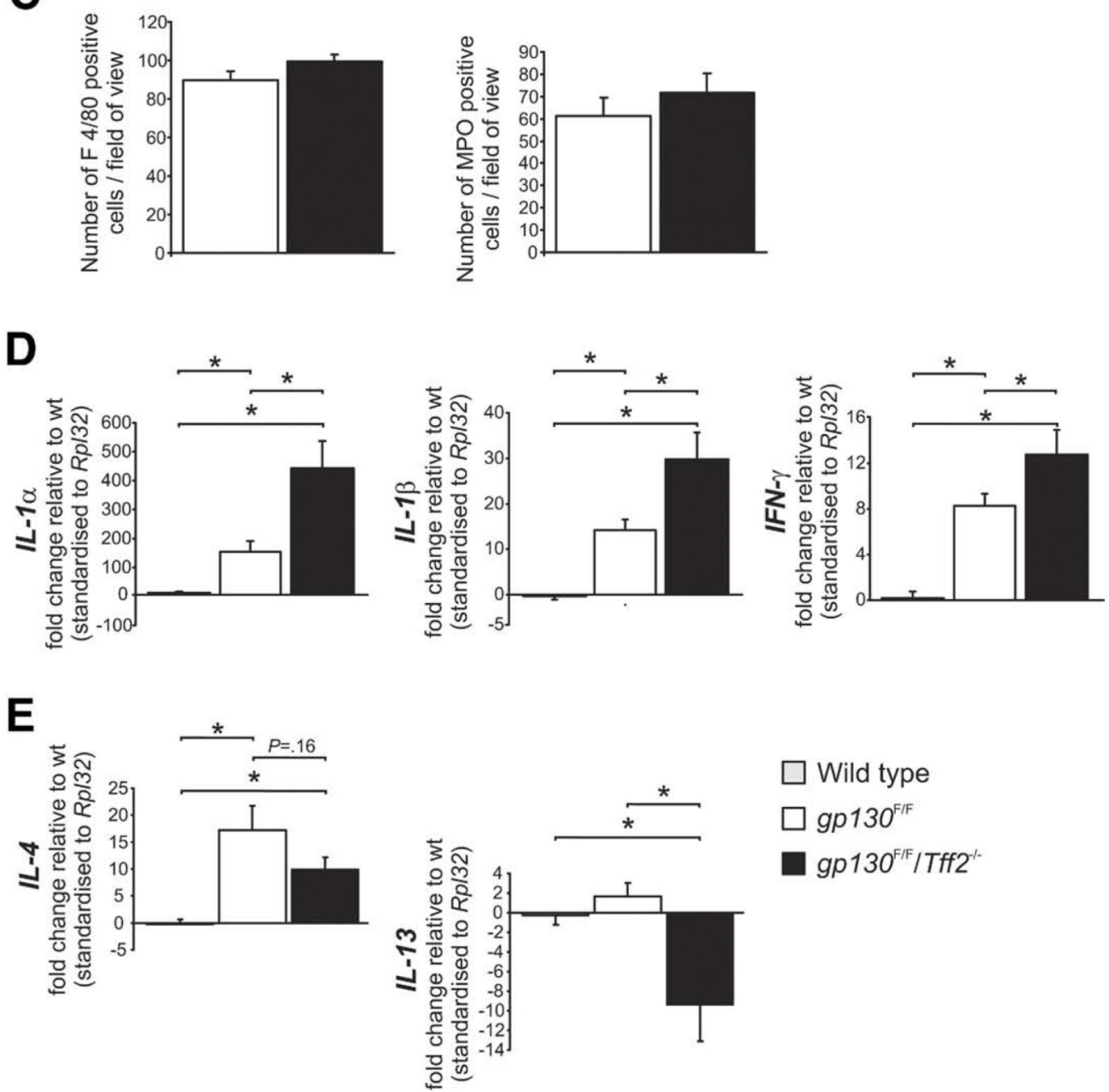

Figure 5.

Analysis of inflammatory mediators in $g p 130^{\mathrm{F} / \mathrm{F}} / T f f 2^{-/-}$antral tumors. (A) Representative $\mathrm{H} \& \mathrm{E}$ sections showing intramucosal inflammation in the lamina propria within tumors; scale bar shows $50 \mu \mathrm{m}$. (B) Semiquantitative gradation of tumor-associated inflammatory leukocyte infiltrate. $(C)$ Quantitative immunohistochemistry of tumor-associated, activated macrophages $(F 4 / 80)$ and neutrophils $(M P O)$. QRT-PCR expression analysis in antral tumors of $(D)$ Th1 cytokines: ILla, ILI $\beta, I F N \gamma$. (E) Th2 cytokines: IL-13, IL-4. Histograms show mean messenger RNA fold change relative to wild type. Asterisks show statistical significance $(P<.05)$. 
A
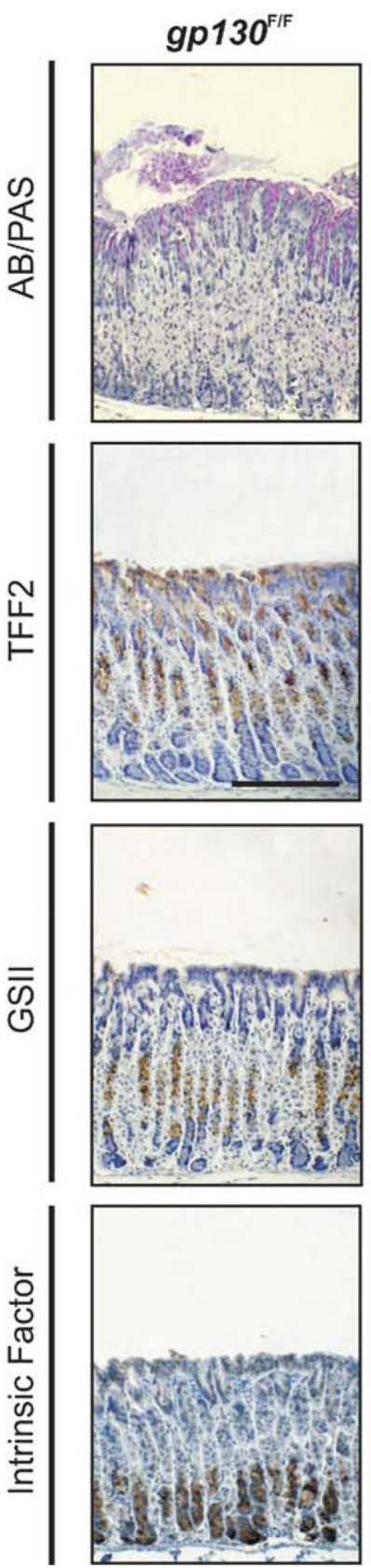
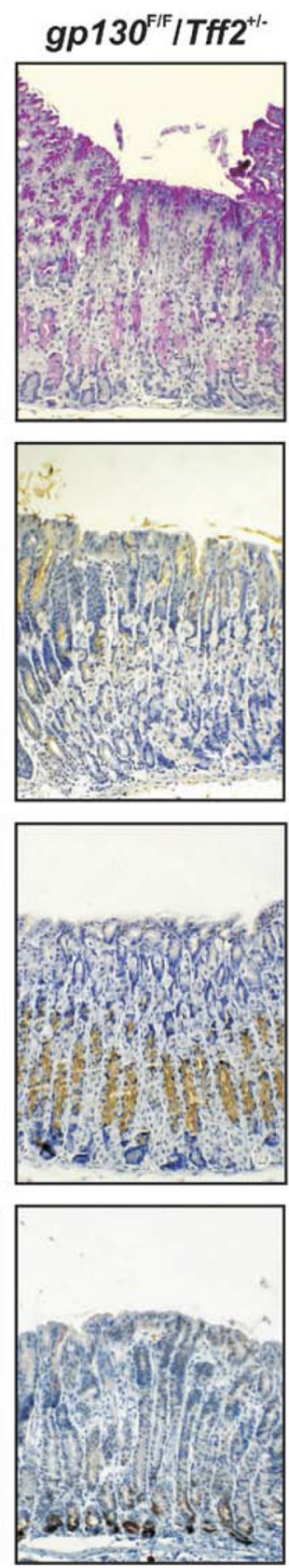

B
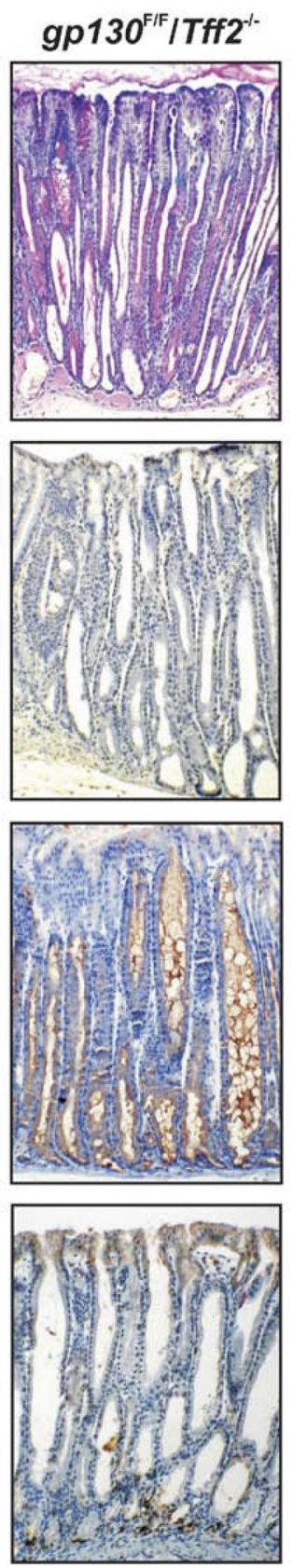
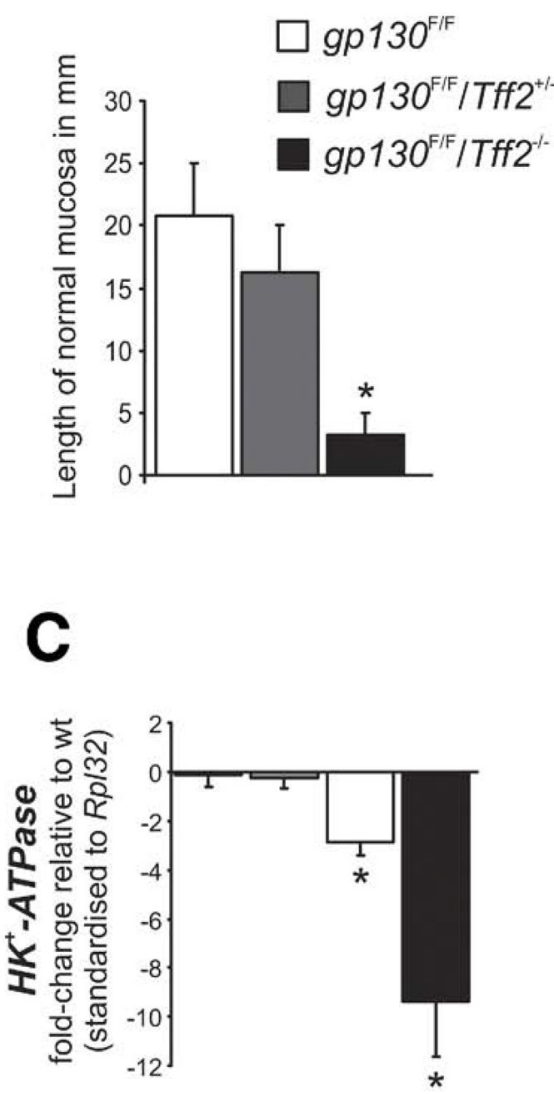

Figure 6.

Analysis of fundic atrophy in $g p 130^{\mathrm{F} / \mathrm{F}} / T f f 2^{-/-}$mice. (A) Immunohistochemical localization of Tff2 (MNCs), intrinsic factor (chief cells), GSII (MNCs); neutral/acidic mucins ( $A B /$ $P A S)$. Scale bar shows $50 \mu \mathrm{m}$. (B) Quantitative morphometry of normal vs atrophic fundic mucosa. (C) QRT-PCR analysis of $\mathrm{H}^{+} \mathrm{K}^{+} \mathrm{ATPase}$ expression; histogram shows mean messenger RNA fold change relative to wild type. Asterisks show statistical significance $(P$ $<.05)$. 
A
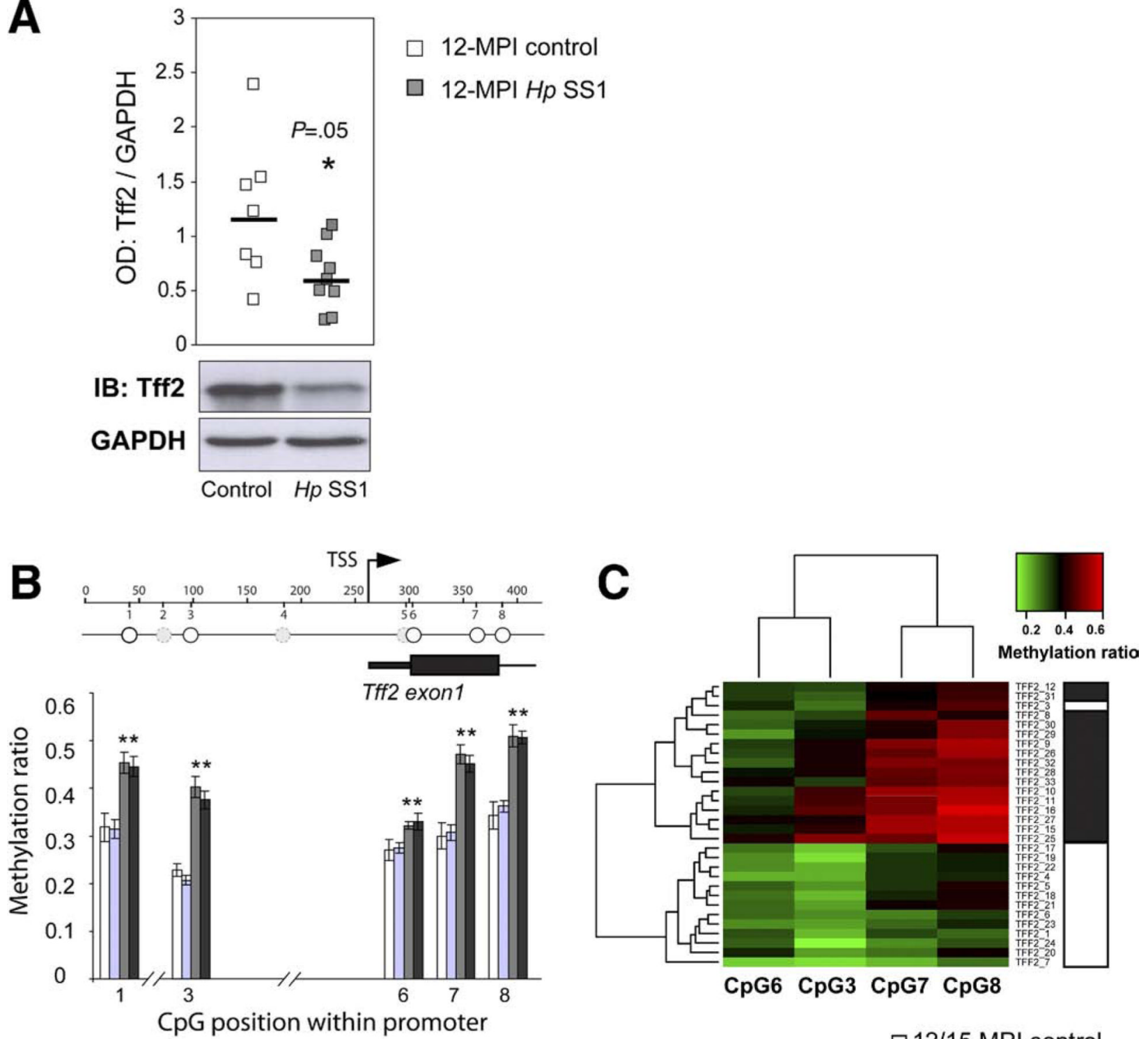

口12-MPI control

$\square 12 / 15 \mathrm{MPI}$ control

口15-MPI control

\section{$\square 12-M P I H p$ SS1}

$\square 15-\mathrm{MPI} H \mathrm{H}$ SS1

Figure 7.

Tff2 2 promoter methylation is induced by experimental $H$ pylori infection in mice. $(A)$ Immunoblot analysis of Tff2 protein expression in stomachs of wild-type (C57BL6) mice at 12-month postinfection (12-MPI) with H pylori SS1 ( $\mathrm{Hp}$ SS1) compared with noninfected controls. Horizontal black bars show mean optical density (OD) of Tff 2 protein bands normalized to GAPDH. Representative protein bands from each group are shown below the scatterplots. (B) Quantitative Tff2 promoter methylation analysis (EPITYPER) in 12 and 15 MPI Hp SS1 and control stomach. Histograms show mean CpG methylation ratios. Asterisks show statistical significance $(P<.05)$. Wide black box shows exon1 coding region; narrow 
black box shows exon1 5' UTR; transcription start site (TSS); base pair (bp) positions are indicated; solid-line circles show CpGs covered by the analysis; broken-line circles show nonanalyzed CpGs. (C) Two-way hierarchical cluster analysis of Tff2 promoter methylation data (columns) against mouse samples (rows). Hp SS1 infection status classification is shown on the right: white boxes (12/15 MPI noninfected controls), black boxes (12/15 MPI Hp SS1). CpG methylation ratios: 0.2 (green; low) to 0.6 (red; high; see color key). 